\title{
Revisiting backward recall and benchmark memory effects: a reply to Bireta et al. (2010)
}

\author{
Katherine Guérard • Jean Saint-Aubin • \\ Samantha C. Burns $\cdot$ Cindy Chamberland
}

Published online: 12 November 2011

(C) Psychonomic Society, Inc. 2011

\begin{abstract}
When participants are asked to recall lists of items in the reverse order, known as backward recall, several benchmark memory phenomena, such as the word length effect, are abolished (Bireta et al. Memory \& Cognition 38:279-291, 2010). Bireta et al. (Memory \& Cognition 38:279-291, 2010) suggested that in backward recall, reliance on order retention is increased at the expense of item retention, leading to the abolition of itembased phenomena. In a subsequent study, however, Guérard and Saint-Aubin (in press) showed that four lexical factors known to modulate item retention were unaffected by recall direction. In a series of five experiments, we examined the source of the discrepancy between the two studies. We revisited the effects of phonological similarity, word length, articulatory suppression, and irrelevant speech, using open and closed pools of words in backward and forward recall. The results are unequivocal in showing that none of these effects are influenced by recall direction, suggesting that Bireta et al.'s (Memory \& Cognition 38:279-291, 2010) results are the consequence of their particular stimuli.
\end{abstract}

Katherine Guérard, École de psychologie, Université de Moncton; Jean Saint-Aubin, École de psychologie, Université de Moncton; Samantha C. Burns, École de psychologie, Université de Moncton; Cindy Chamberland, École de psychologie, Université de Moncton.

This research was supported by discovery grants from the Natural Sciences and Engineering Research Council of Canada to Jean SaintAubin and to Katherine Guérard. Samantha Burns was supported by an undergraduate student research award. Thanks are due to Isabelle Cormier, Marilyne Maltais, Marie-Andrée Légère, and Marie-Claire Losier for assistance in running the experiments.

K. Guérard $(\bowtie) \cdot J$. Saint-Aubin · S. C. Burns · C. Chamberland

École de Psychologie, Université de Moncton,

Moncton, New Brunswick E1A 3E9, Canada

e-mail: katherine.guerard@umoncton.ca
Keywords Immediate memory - Backward recall . Phonological similarity · Word length · Articulatory suppression · Irrelevant speech

Immediate memory is typically studied using forward serial recall, in which participants are required to recall lists of items in the same order as that in which they have been presented. Immediate memory is also investigated with a variant of this task, known as backward recall, in which participants recall list items in the reverse order (see, e.g., Banken, 1985; Reynolds, 1997). In two articles, Bireta and her colleagues (Bireta et al., 2010; Surprenant et al., 2011) showed that four benchmark memory phenomena-that is, the effects of phonological similarity, word length, articulatory suppression, and irrelevant speech-were abolished or greatly diminished in backward recall. To account for this finding, they suggested that more attention is devoted to order retention in backward recall than in forward recall. The higher level of attention to order retention would come at the expense of item retention, leading to the abolition of item-based phenomena. Guérard and Saint-Aubin (in press) tested this hypothesis by manipulating four lexical variables well known to affect item retention (see, e.g., Saint-Aubin $\&$ Poirier, 1999). They showed that the effects of semantic similarity, word frequency, word imagery, and lexicality were immune to the influence of recall direction. Guérard and Saint-Aubin suggested that the discrepancy between their results and those of Bireta and her colleagues could be due to the fact that benchmark memory phenomena and long-term effects are based on distinct processes (see Stuart \& Hulme, 2009). Another possibility, however, is that this discrepancy is due to methodological differences between the two studies. For instance, Bireta et al. (2010) used closed sets of words or letters in all their experiments, 
whereas Guérard and Saint-Aubin used open sets of words. The objective of the present study was to examine the source of the discrepancy between the two studies to improve our understanding of the processes involved in backward recall. In order to do this, we revisited the effects of phonological similarity, irrelevant speech, articulatory suppression, and word length in forward and backward recall, using open and closed pools of words.

After more than a century of work on the processes involved in forward immediate serial recall, there has been growing interest in understanding the processes involved in backward recall (see, e.g., Lewandowsky \& Farrell, 2008). In order to further understand these processes, Bireta et al. (2010; see also Surprenant et al., 2011) tested four benchmark memory phenomena well known to modulate forward serial recall performance in backward recall - that is, the effects of word length, phonological similarity, articulatory suppression, and irrelevant speech. Bireta and her colleagues (2010; Surprenant et al., 2011) showed that the four benchmark memory effects are abolished or greatly reduced in backward recall, as compared with forward recall. They accounted for these results within the scale invariant memory and perceptual learning (SIMPLE) model (Brown, Neath, \& Chater, 2007). SIMPLE suggests that benchmark memory effects occur at the level of the item dimension. Bireta et al. (2010) suggested that benchmark memory phenomena were abolished in backward recall because, in this recall condition, more attention is devoted to the order dimension at the expense of the item dimension. As a consequence, the phenomena that occur because of the item dimension are abolished or greatly diminished.

Other factors that are well known to modulate item retention are lexical variables. Lexical variables refer to "word properties, such as word frequency and concreteness, which reflect differences in the way in which words are represented in long-term or lexical memory" (Stuart \& Hulme, 2009, p. 157). Lexical effects include the better recall of high-frequency words over lowfrequency words (the word frequency effect; see, e.g., Hulme, Stuart, Brown, \& Morin, 2003; Roodenrys \& Quinlan, 2000), of words over nonwords (the lexicality effect; see, e.g., Hulme, Maughan, \& Brown, 1991; Multhaup, Balota, \& Cowan, 1996), of concrete words over abstract words (the effect of word concreteness or imageability; see, e.g., Miller \& Roodenrys, 2009; Walker \& Hulme, 1999), and of semantically related words over unrelated words (the effect of semantic similarity; see, e.g., Poirier \& Saint-Aubin, 1995; Tse, 2009). Saint-Aubin and Poirier (1999) showed that lexical variables modulate item retention. Guérard and Saint-Aubin (in press) reasoned that if backward recall reduces the availability of resources for the item dimension, lexical effects should be abolished in backward recall. Contrary to this prediction, they showed that the effects of lexicality, word frequency, word imagery, and semantic similarity were generally unaffected by backward recall (see also Walker \& Hulme, 1999).

At first glance, backward recall appears as a further dissociation between short- and long-term memory processes. However, before considering backward recall effects as a new dissociation, some key methodological issues must be addressed. The word pool appears to be a good candidate to account for previous dissociations. With a backward recall procedure, lexical effects were maintained in previous studies using an open word pool in which different words were presented on each trial (Guérard \& Saint-Aubin, in press; Walker \& Hulme, 1999). On the other hand, lexical effects were abolished with a closed pool where the same items were used on every trial (Hulme et al., 1997). Similarly, Bireta and her colleagues (2010; Surprenant et al., 2011) abolished or reduced all benchmark memory effects with closed or semi-closed pools. A semi-closed pool is a word set that is restricted but larger than list length, so that the same items are repeated several times during an experiment. In forward recall, it is well established that set size modulates both lexical (see, e.g., Roodenrys \& Quinlan, 2000) and benchmark (see, e.g., Gupta, Lipinski, \& Aktunc, 2005) memory effects. For instance, Roodenrys and Quinlan showed that the effect of word frequency was reduced when a closed pool of words was used, as compared with an open pool of words. They suggested that set size influenced item retrieval by reducing the number of competitors during redintegration. Likewise, the phonological similarity effect on item memory has been reduced with a closed pool (Gupta et al., 2005). The different levels of requirements in terms of item memory between open and closed pools might modulate the effect of backward recall and the attentional shift between item and order retention.

In the following series of experiments, we revisited the four benchmark memory phenomena studied by Bireta et al. (2010), using open and closed pools of words. We manipulated phonological similarity, irrelevant speech, articulatory suppression, and word length in both forward and backward recall. Prior knowledge of recall direction was shown not to modulate the effect of recall direction on the benchmark memory effects (see Surprenant et al., 2011) and on the lexical effects (see Guérard \& Saint-Aubin, in press). Therefore, for the sake of comparability with the previous studies, participants were informed of recall direction only after list presentation. Moreover, in order to compare our results with those of previous studies, an order reconstruction procedure similar to that adopted by Bireta et al. (2010) was used. 


\section{Experiment 1: phonological similarity}

In Experiments $1 \mathrm{~A}$ and $1 \mathrm{~B}$, we tested the effect of phonological similarity, which is the better recall of dissimilar sounding items over similar sounding items (Baddeley, Lewis, \& Vallar, 1984; Conrad, 1964). The effect of phonological similarity was assessed using an open pool of words (Experiments 1A) and a closed pool of words (Experiment 1B).

\section{Experiment 1A}

\section{Method}

Participants Twenty undergraduate students from Université de Moncton volunteered to participate in this experiment.

Materials A total of 56 lists were assembled. Twenty-eight phonologically similar lists were composed of seven monosyllabic French words that rhymed together. Each word was used only once for phonologically similar lists, and the same rhyme was not used for more than four lists. In order to assemble the lists of 28 dissimilar words, the 28 similar lists were split into four sets of 7 lists, with the constraint that none of the 7 lists could share a rhyme. Seven dissimilar lists were assembled by selecting at random 1 word from each phonologically similar list of a set. With this procedure, each word was used twice: once for a phonologically similar list and once for a phonologically dissimilar list. Therefore, the words in the similar and dissimilar conditions were equated on all possible variables.

Design Each participant underwent one block of 56 experimental trials preceded by 4 practice trials, 2 for each recall direction. The practice trials were done with the experimenter present to ensure compliance with the instructions. The lists in the four conditions (forward dissimilar, forward similar, backward dissimilar, backward similar) were presented in a different random order for each participant. The words within each list were also presented in a different random order for each participant. The two sets of lists used in forward and backward recall were counterbalanced across participants. The experiment lasted about $45 \mathrm{~min}$.

Procedure The words were presented sequentially at the center of the screen at a rate of one item per second $(1,000 \mathrm{~ms}$ on, $0 \mathrm{~ms}$ off). After the presentation of the last word, they all reappeared simultaneously on the screen and were to be clicked on in the correct order - that is, from the first to the last item in forward recall or from the last to the first item in backward recall. The items reappeared in alphabetical order and were presented in two rows containing three and four items, respectively. Once clicked upon, the words changed from black color to green. The recall direction was indicated by the word "normal" (normal) in blue or "inversé" (reverse) in red capital letters above the symbol " $==>$ " or " $<==$ " presented in black ink in the upper part of the screen, above the to-be-recalled words. The words remained on the screen until each one had been clicked on. The order in which the words were clicked upon was recorded by the computer. Therefore, if, in the backward recall condition, participants started with the first presented word, followed by the second presented word, as in forward recall, those responses would be considered as errors, because the correct answers are the seventh and sixth items, respectively. Participants self-initiated trials by pressing the space bar.

\section{Results}

All repeated measures analyses of variance (ANOVAs) conducted on the proportions of correct responses in the following experiments are reported in Appendix 1. In all analyses, the .05 level of significance was adopted, and the Greenhouse-Geisser correction was applied when the sphericity criterion was not met. The two top left panels of Fig. 1 show a phonological similarity effect in both recall conditions. As can be seen in Appendix 1, the recall performance did not vary between the forward recall $(M=.51, S D=.13)$ and backward recall $(M=.54, S D=.17)$ conditions. Phonologically dissimilar words $(M=.59, S D=.15)$ were better recalled than phonologically similar words $(M=.47$, $S D=.13)$, and the main effect of serial position was significant. Importantly, there was no significant interaction between recall direction and phonological similarity. The significant interaction between recall direction and serial position corresponded to the typical greater primacy effect in forward recall and to the greater recency effect in backward recall. There was also a significant interaction between phonological similarity and serial position. No other interactions were significant.

Despite the nonsignificant interaction between recall direction and serial position, planned contrasts were carried out in order to confirm the presence of a phonological similarity effect in forward and backward recall. The contrasts for all experiments are reported along with the effect sizes (Cohen's $d$ ) and the magnitude of the memory effects (see Surprenant, Neath, Bireta, \& Allbritton, 2008) in each of the forward and backward conditions in Table 1. For instance, the magnitude of the phonological similarity effect was given as a percentage by calculating the difference in recall performance between the dissimilar and similar condi- 
Fig. 1 Proportion of correct responses as a function of serial position in the forward and backward recall directions in Experiments 1-4. Errors bars represent $95 \%$ confidence intervals
Phonological Similarity (Exp.1A)
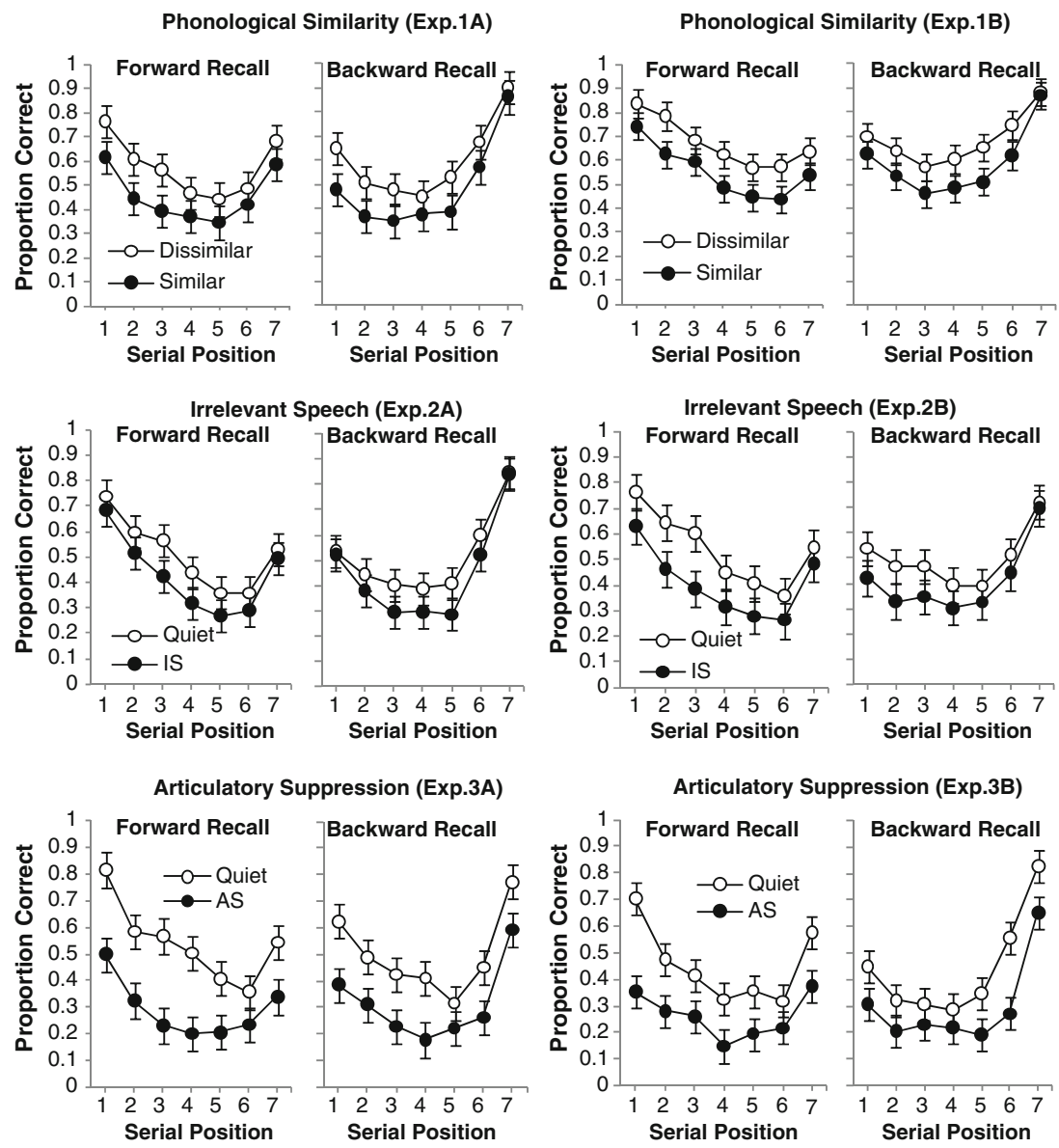

Word Length (Exp.4A)
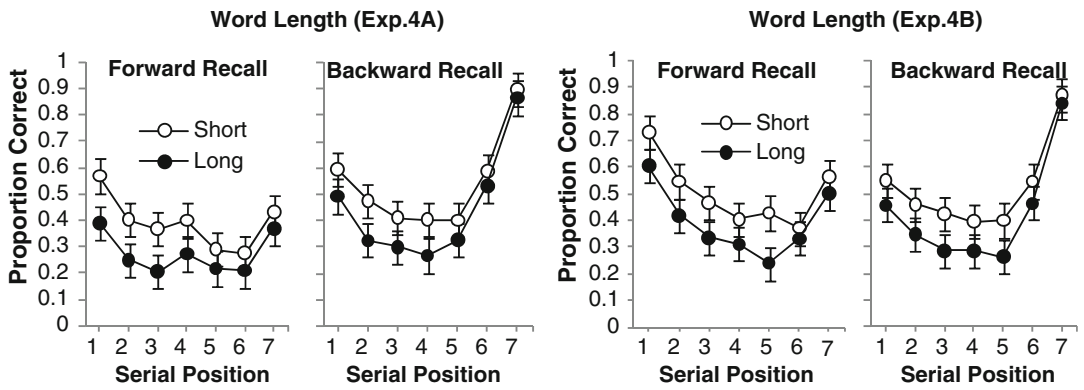

tions, divided by recall performance in the dissimilar condition ( [(Dis Sim)/Dis] $* 100)$. Table 1 shows that the phonological similarity effect was significant in both forward and backward recall.

\section{Discussion}

As in previous studies, phonologically similar words were more difficult to recall than dissimilar words (see, e.g., Baddeley et al., 1984; Conrad, 1964). In contrast with the results of Bireta et al. (2010), phonologically similar words were more difficult to recall than dissimilar words for both forward and backward recall: Recall direction had no effect on the phonological similarity effect.

\section{Experiment 1B}

The discrepancy between our results and those of Bireta et al. (2010) could be due to their stimuli. First, Bireta et al. (2010) used a closed pool of items, whereas we used an open pool. As was suggested by Roodenrys and Quinlan (2000), decreasing set size might influence memory performance by restraining the pool of candidates that compete for output at recall. This could promote the reliance on order retention in backward recall. Second, Bireta et al. (2010) used letters, which are highly familiar items, whereas we used words. Experiment 1B was designed to control for these two factors. We used a closed pool of words so that for each participant, the same two sets 
Table 1 Planned contrasts, Cohen's $d$ and magnitude of the memory effects (\%) in each of the forward and backward recall conditions, in Experiments 1-5

\begin{tabular}{|c|c|c|c|c|c|c|c|c|c|c|c|}
\hline \multirow[t]{2}{*}{ Pool (Exp.) } & \multirow[b]{2}{*}{$d f$} & \multicolumn{5}{|l|}{ Forward } & \multicolumn{5}{|c|}{ Backward } \\
\hline & & $F$ & $M S E$ & $\eta_{p}^{2}$ & $d$ & Magnitude (\%) & $F$ & $M S E$ & $\eta_{p}^{2}$ & $d$ & Magnitude (\%) \\
\hline \multicolumn{12}{|c|}{ Phonological Similarity } \\
\hline Open (1A) & 1,19 & $10.72 *$ & .01 & .36 & 0.69 & 20.8 & $16.80^{*}$ & .01 & .47 & 0.91 & 19.0 \\
\hline Closed (1B) & 1,19 & $20.98^{*}$ & .01 & .53 & 0.65 & 17.9 & $14.20^{*}$ & .01 & .43 & 0.62 & 14.3 \\
\hline \multicolumn{12}{|l|}{ Irrelevant Speech } \\
\hline Open $(2 \mathrm{~A})$ & 1,19 & $11.74 *$ & .01 & .38 & 0.61 & 16.4 & $9.75^{*}$ & .01 & .34 & .56 & 13.4 \\
\hline Closed (2B) & 1,19 & $44.97 *$ & .00 & .70 & 1.03 & 25.1 & $17.55^{*}$ & .01 & .48 & 0.70 & 17.9 \\
\hline \multicolumn{12}{|c|}{ Articulatory Suppression } \\
\hline Open (3A) & 1,19 & $88.64 *$ & .01 & .82 & 2.41 & 46.1 & $67.07^{*}$ & .01 & .78 & 1.96 & 37.6 \\
\hline Closed (3B) & 1,19 & $41.86^{*}$ & .01 & .69 & 1.64 & 42.3 & $78.55^{*}$ & .00 & .81 & 1.45 & 32.9 \\
\hline \multicolumn{12}{|l|}{ Word Length } \\
\hline Open (4A) & 1,19 & $15.05^{*}$ & .01 & .44 & 0.94 & 29.9 & $17.18^{*}$ & .01 & .48 & 0.67 & 17.5 \\
\hline Closed (4B) & 1,19 & $35.96^{*}$ & .00 & .65 & 0.83 & 21.9 & $14.16^{*}$ & .01 & .43 & 0.78 & 19.3 \\
\hline Semi-closed (5) & 1,19 & $26.67^{*}$ & .01 & .58 & 1.22 & 29.5 & $7.75^{*}$ & .00 & .29 & 0.54 & 10.7 \\
\hline
\end{tabular}

$* p<.05$

of similar and dissimilar words were presented in every trial, but in a different random order. In order to ensure that the effects are not attributable to the selected stimuli, the stimulus sets were different for each participant. Finally, the effect of familiarity was examined by increasing the number of trials. A total of 80 trials, divided into four blocks of 20 trials, were implemented. If item familiarity modulates the interaction between recall direction and phonological similarity, the similarity effect should decrease as a function of block in backward recall, but not in forward recall.

\section{Method}

Participants Twenty undergraduate students from Université de Moncton volunteered to participate in this experiment. None had participated in the previous experiments.

Materials The materials were the same as those used in Experiment 1A. However, to meet the conditions of the closed pool needed for this experiment, the same phonologically similar and dissimilar lists were used throughout the experiment; for each participant, the two lists were chosen from those used in Experiment 1A, with the restriction that one word was not repeated between the phonologically similar and dissimilar lists. On each trial, the same words were presented in a different randomized order. Importantly, the stimulus set was different for each participant.

Design and procedure The design and procedure were the same as those in Experiment 1A, with the exception that the present experiment consisted of four blocks of 20 trials. In each block, there were 5 trials per condition (forward dissimilar, forward similar, backward dissimilar, backward similar) that were presented randomly. The 80 trials were presented in succession so that participants were not aware that there were four separate blocks of trials. The experiment lasted approximately $1 \mathrm{~h}$.

\section{Results}

In order to examine the role of familiarity in the abolition of the phonological similarity effect in backward recall, the 80 experimental trials were divided into four blocks of 20 trials (see Fig. 2). Recall performance was pooled across serial positions. A 2 (recall direction) $\times 2$ (phonological similarity) $\times$ 4 (block) repeated measures ANOVA showed that dissimilar words were better recalled than similar words, $F(1,19)=$ 22.47, MSE $=.04, \eta_{p}^{2}=.54$, and that performance improved as a function of block, $F(3,57)=3.47, M S E=.02, \eta_{p}^{2}=.15$. The effect of recall direction was not significant, $F(1,19)=$ $1.57, M S E=.03, \eta_{p}^{2}=.08$. No interactions were significant.

Since block did not modulate the effect of backward recall on the phonological similarity effect, we analyzed performance as a function of serial position, pooled across the four blocks. The serial position curves illustrated in the two top right panels of Fig. 1 show a phonological similarity effect in both forward recall and backward recall. The repeated measures ANOVA reported in Appendix 1 revealed that the main effect of serial position was 


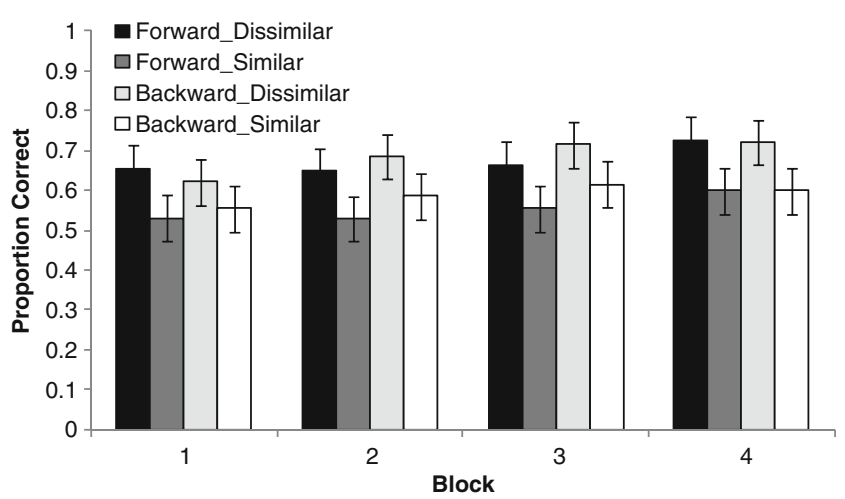

Fig. 2 Proportion of correct responses as a function of block, recall direction, and phonological similarity in Experiment 1B. Errors bars represent $95 \%$ confidence intervals

significant but that performance in backward $(M=.64$, $S D=.13)$ and forward $(M=.61, S D=.12)$ recall was not significantly different. Phonologically dissimilar words $(M=.68, S D=.18)$ were better recalled than phonologically similar words $(M=.57, S D=.15)$. Once again, there was no significant interaction between recall direction and phonological similarity. Moreover, planned contrasts confirmed that the effect of phonological similarity was significant in both forward and backward recall (see Table 1). Cohen's ds calculated in both conditions suggest that the effect of phonological similarity was similar in the backward and in the forward conditions. The interaction between recall direction and serial position was significant, indicating that the primacy effect was greater in forward recall, whereas the recency effect was greater in backward recall. There were no other significant interactions.

\section{Discussion}

Experiment 1B replicates previous studies in showing that phonologically similar items are more difficult to recall than dissimilar items (see, e.g., Baddeley et al., 1984; Conrad, 1964). Most important, the effect of phonological similarity was unaffected by recall direction, irrespective of whether participants were unfamiliar (in Block 1) or familiar (in Block 4) with the stimuli. This suggests that item familiarity does not mediate the abolition of the phonological similarity effect in backward recall.

\section{Experiment 2: irrelevant speech}

Experiment 1 showed that, unlike in Bireta et al. (2010), the effect of phonological similarity was observed in forward and backward recall, irrespective of set size and item familiarity. In Experiment 2, we revisited a second benchmark memory effect abolished in backward recall by Bireta et al. (2010) - that is, the effect of irrelevant speech.
This effect is observed when irrelevant tokens presented auditorily during the memory task impair recall performance (Colle \& Welsh, 1976; Cowan, Lichty, \& Grove, 1990; Jones \& Morris, 1992; LeCompte, 1996). The effect of irrelevant speech was tested in forward and backward recall using an open (Experiment 2A) and a closed (Experiment 2B) pool of words.

\section{Method}

Participants Forty students from a local college volunteered to participate in this experiment. Twenty took part in Experiment 2A, and 20 took part in Experiment 2B.

Materials In Experiment 2A, two word pools containing 196 monosyllabic French nouns were used; the words within each pool were matched for word frequency. From each pool, 28 lists of seven words were assembled by sampling without replacement, with the constraint that, within each list, there were no rhyming words and no obvious semantic associations between words. For each pool, the 28 lists were randomly split into two sets of 14 lists. At the end of this procedure, we obtained four sets of 14 lists, each presented in one of the four conditions of the experiment (forward/quiet, forward/irrelevant speech, backward/quiet, backward/irrelevant speech). Using a Latin square design, each set was used equally often in each of the four conditions. In order to meet the conditions of a closed pool in Experiment $2 \mathrm{~B}$, the lists of words used for each trial of an individual participant were composed of the same seven words in randomized order, the words being taken from an original list randomly chosen from the pool used in Experiment 2A. The stimulus set was different for each participant. A sequence of 27 digits from 1 to 9 presented in random order was used for the irrelevant speech condition of the experiment. The digits were spoken by a male voice through headphones at a rate of one item per $300 \mathrm{~ms}$. The same list of digits was used for all trials and all participants.

Design and procedure The design and procedure were the same as those used in Experiment 1A, with the exception that on $50 \%$ of the trials, to-be-ignored digits were presented to the participants over the headphones during the presentation of the words. The presentation of spoken digits began 1,000 $\mathrm{ms}$ before the onset of the first word and ended $100 \mathrm{~ms}$ after the offset of the last word.

\section{Results}

An examination of Fig. 1 shows an irrelevant speech effect for both forward and backward recall conditions. The 
pattern of performance was the same in both Experiments $2 \mathrm{~A}$ and $2 \mathrm{~B}$.

Experiment $2 A$ The analysis revealed a significant better recall under quiet $(M=.51, S D=.12)$ than under irrelevant speech $(M=.44, S D=.12)$ conditions. Backward $(M=.48$, $S D=.05)$ and forward $(M=.47, S D=.06)$ recall performance was not significantly different, but the effect of serial position was significant. The interaction between recall direction and irrelevant speech was not significant. There was a significant interaction between recall direction and serial position, caused by the greater primacy effect in forward recall and the greater recency effect in backward recall. A significant interaction between irrelevant speech and serial position was also observed. No other significant interactions were found. As is shown in Table 1, planned contrasts confirmed that the effect of irrelevant speech was significant in both forward and backward recall conditions.

Experiment $2 B$ The results of our analysis, reported in Appendix 1, revealed that backward $(M=.45, S D=.12)$ and forward $(M=.47, S D=.12)$ recall did not differ significantly but that recall performance was superior in the quiet condition $(M=.52, S D=.12)$, as compared with the irrelevant speech condition $(M=.41, S D=.11)$. The main effect of serial position was also significant. It is important to note that no significant interaction was found between recall direction and irrelevant speech. Planned contrasts confirmed that the effect of irrelevant speech was significant in both recall directions (see Table 1). The interaction between recall direction and serial position was significant, confirming the greater primacy effect in forward recall and recency effect in backward recall. The interaction between irrelevant speech and serial position was also significant, but no other interactions were significant.

Discussion In both Experiments 2A and 2B, we replicated the detrimental effect of irrelevant speech on the recall of words (see, e.g., Colle \& Welsh, 1976; Cowan et al., 1990; Jones \& Morris, 1992; LeCompte, 1996). In opposition to Bireta et al.'s (2010) results, the irrelevant speech effect was found in both forward and backward recall, irrespective of set size.

\section{Experiment 3: articulatory suppression}

When participants are asked to articulate irrelevant items during memorization of the list in serial recall, their performance is greatly impaired, as compared with a control condition with no concurrent articulation (the effect of articulatory suppression; see, e.g., Baddeley et al., 1984;
Murray, 1968). Bireta et al. (2010) showed that this effect was reduced in backward recall. The effect of articulatory suppression was tested in forward and backward recall using an open (Experiment 3A) and a closed (Experiment 3B) pool of words.

\section{Method}

Participants Forty students from a local college volunteered to participate in this experiment. Twenty took part in Experiment 3A, and 20 took part in Experiment 3B.

Materials The materials in Experiment 3A and 3B were the same as those used in Experiments 2A and 2B, respectively, with the exception that no irrelevant speech was used.

Design and procedure The design and procedure were the same as those in Experiment $1 \mathrm{~A}$, with the exception that $1,000 \mathrm{~ms}$ before the presentation of the first to-be-remembered word on the screen, participants were presented with either the word "silence" (in the condition without articulatory suppression) or the numbers "1-2-3-4" (in the condition with articulatory suppression) in the center of the screen. Half of the trials were assigned to the quiet condition, and the other half were assigned to the articulatory suppression condition. When submitted to the articulatory suppression condition, participants were required to count from 1 to 4 repetitively during the entire presentation of the to-be-remembered stimuli, whereas during the silence condition, participants were instructed not to count.

\section{Results}

As is shown in Fig. 1, forward and backward recall conditions showed an effect of articulatory suppression in both Experiments 3A and 3B.

Experiment $3 A$ The analysis indicated that recall performance did not significantly differ in the backward $(M=.41$, $S D=.17)$ and forward $(M=.42, S D=.18)$ conditions. The absence of articulatory suppression during stimuli presentation $(M=.52, S D=.11)$ generated better recall performance than did the presence of articulatory suppression $(M=.30, S D=.07)$. The main effect of serial position was significant. As is suggested by the significant interaction between recall direction and articulatory suppression, the effect of articulatory suppression was greater in forward recall than in backward recall. Planned contrasts showed that the effect of articulatory suppression was significant in both forward and backward recall (see Table 1). The interaction between recall direction and serial position and 
the interaction between articulatory suppression and serial position were significant. No other significant interactions were found.

Experiment $3 B$ The analysis confirmed that recall performance was superior in the quiet condition $(M=.45, S D=.11)$ than in the articulatory suppression condition $(M=.28$, $S D=.09)$. Recall performance was not significantly different in the backward $(M=.37, S D=.10)$ and forward $(M=.36$, $S D=.10)$ conditions, but the effect of serial position was significant. Importantly, there was no significant interaction between recall direction and articulatory suppression in this experiment. Planned contrasts confirmed that the effect of articulatory suppression was significant in both forward and backward recall (see Table 1). The interaction between recall direction and serial position was significant, consistent with the greater primacy and recency effects found in forward and backward recall, respectively. A significant three-way interaction between recall direction, articulatory suppression, and serial position was also found, although no other significant interactions were found.

\section{Discussion}

An effect of articulatory suppression on recall performance was found in Experiments 3A and 3B (see, e.g., Baddeley et al., 1984; Murray, 1968). In line with previous experiments, backward recall did not modulate the effect of articulatory suppression in Experiment 3B when a closed pool was used. In Experiment $3 \mathrm{~A}$, however, when an open pool of words was used, backward recall reduced the magnitude of the effect of articulatory suppression. This diminution was rather weak, however, decreasing from $46.1 \%$ in forward recall to $37.6 \%$ in backward recall (see Table 1), a reduction of $8.5 \%$. Indeed, in Bireta et al.'s (2010) study, the magnitude of the effect of articulatory suppression went from $54.5 \%$ in forward recall to $25.8 \%$ in backward recall, a reduction of $28.7 \%$.

\section{Experiments 4 and 5: word length}

The effect of word length refers to the better recall of short words over long words (see, e.g., Baddeley, Thomson, \& Buchanan, 1975). This effect was abolished in backward recall (Bireta et al., 2010; Surprenant et al., 2011). In the following experiments, word length was reassessed in forward and backward recall, using an open pool of words (Experiment 4A), a closed pool of words (Experiment 4B), and the same semi-closed pool of words as that used by Bireta et al. (2010; Experiment 5).
Experiment 4

Method

Participants Forty students from a local college volunteered to participate in this experiment. Twenty took part in Experiment 4A, and 20 took part in Experiment 4B.

Materials In Experiment 4A, two word pools containing 196 words each were used for this experiment. The first pool, used for the short-word condition, consisted of monosyllabic nouns, whereas the second pool, used for the long-word condition, was composed of three-syllable nouns. Both pools were equated for word frequency and imagery. Each pool was divided to make 28 lists of seven words, with the condition that, within each list, there were no rhyming words or obvious semantic associations between words. The same materials were used in Experiment $4 \mathrm{~B}$, except that, in order to meet the conditions of a closed pool, the lists of words used for each trial of an individual participant were composed of the same words in randomized order, the words being taken from an original list randomly chosen from the pool used in Experiment 4A.

Design and procedure The design and procedure were the same as those in Experiment 1A.

\section{Results}

An examination of Fig. 1 shows a word length effect in both recall conditions, in both Experiments 4A and 4B.

Experiment $4 A$ The analyses indicated that the main effects of recall direction, word length, and serial position were all significant: Backward recall $(M=.49, S D=.13)$ resulted in better recall performance than did forward recall $(M=.33$, $S D=.10)$, and short words $(M=.46, S D=.13)$ were better recalled than long words $(M=.36, S D=.11)$. Of particular importance to our study, there was no significant interaction between recall direction and word length. As is shown in Table 1, the effect of word length was significant in forward and backward recall. There was a significant interaction between recall direction and serial position due to the greater primacy effect in forward recall and recency effect of backward recall. There was also a significant interaction between word length and serial position. No other significant interactions were found.

Experiment $4 B$ The analysis showed that backward $(M=.47$, $S D=.19)$ and forward $(M=.45, S D=.13)$ recall performance were not significantly different. There was a significant main effect of word length, with short words $(M=.51, S D=.14)$ being better recalled than long words 
$(M=.41, S D=.10)$. The main effect of serial position was also significant. There was no significant interaction between recall direction and word length. As is shown in Table 1, planned contrasts showed that the effect of word length was significant in forward and backward recall. Once again, there was a significant interaction between recall direction and serial position, as a direct result of the greater primacy effect in forward recall and the greater recency effect in backward recall. There was a significant interaction between word length and serial position. No other interactions were significant.

Discussion In both Experiments 4A and 4B, we replicated the word length effect, showing a recall advantage for short words, as compared with long words (see also Baddeley et al., 1975). In addition, in contrast with the results of Bireta et al. (2010; Surprenant et al., 2011), the effect of word length was not modulated by recall direction, irrespective of set size. Therefore, the four experiments show that the benchmark memory effects are preserved in backward recall. The Cohen's $d$ s presented in Table 1, however, seem to suggest that, in most experiments, the benchmark memory effect is reduced to some extent in backward recall, as compared with forward recall.

Combined analysis In order to examine whether increasing power would allow detecting an effect of recall direction on the memory effects, performance was pooled across serial positions, and word pool was used as a between-subjects factor. Therefore, for each benchmark memory effect, we carried out a mixed ANOVA with pool (two levels; open, closed) as a between-subjects factor and recall direction and benchmark memory phenomenon as within-subjects factors. These analyses are presented in Appendix 2. Recall performance for each experiment, pooled across serial positions, is presented in Fig. 3, along with the results of Bireta et al. (2010) to allow a direct comparison between the two studies.

For the phonological similarity effect (Experiments 1A and 1B), only the main effects of phonological similarity and of pool were significant. The interaction between recall direction and phonological similarity was not significant. A
Fig. 3 Proportion of correct responses in the forward and backward recall directions pooled across serial positions, in Experiments 1-5. The left column shows the proportion of correct recall reported in Bireta et al.'s (2010) study
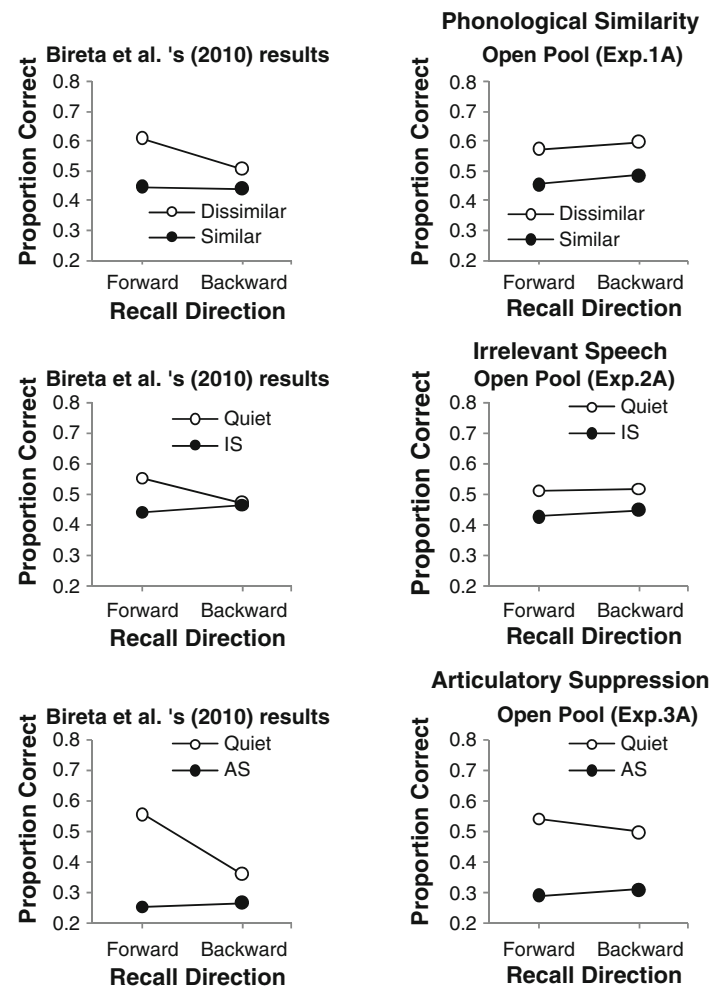

Word Length
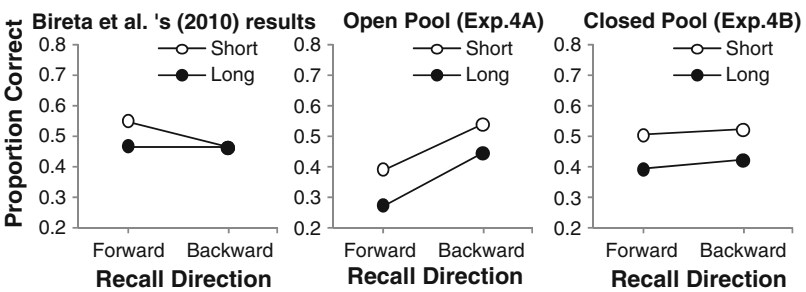
similar pattern was observed for the irrelevant speech effect (Experiments 2A and 2B), showing that only the main effect of irrelevant speech was significant. Indeed, the interaction between recall direction and irrelevant speech was not significant. A different pattern emerged for the effect of articulatory suppression (Experiments $3 \mathrm{~A}$ and $3 \mathrm{~B}$ ): The main effect of articulatory suppression was significant, as well as the interaction between recall direction and articulatory suppression. Finally, for the word length effect (Experiments 4A and $4 \mathrm{~B})$, the main effects of recall direction and of word length were significant. The interaction between recall direction and pool was also significant. As is shown in Fig. 3, this interaction is due to the fact that performance increased in the backward, as compared with the forward, direction when an open pool of words was used (Experiment 4A), but not when a closed pool was used (Experiment 4B). Importantly, the interaction between recall direction and word length was not significant. The combined analyses show that the effects of phonological similarity, irrelevant speech, and word length did not decrease in backward recall. Consistent with the results of Experiment $3 \mathrm{~A}$, only the effect of articulatory suppression was reduced in backward, as compared with forward, recall.

\section{Experiment 5}

In the previous experiments, we showed that the effects of phonological similarity, irrelevant speech, articulatory suppression, and word length were observed in forward and backward recall. Obviously, item familiarity and set size are not the critical factors responsible for modulating the effect of recall direction on these benchmark memory phenomena. What then, could explain the discrepancy between the present results and those of Bireta et al. (2010; Surprenant et al., 2011)? One possibility is that the effects they observed were due to the specific stimulus set they used. In order to test this possibility, we replicated Experiment 4 using the same pool of words as that used by Bireta et al. (2010).

\section{Method}

Participants Twenty students from a local college volunteered to participate in this experiment. All participants were native English speakers, and none had participated in previous experiments.

Materials The materials were the same as those used in the study by Bireta et al. (2010). Two pools were used, the first pool containing 15 monosyllabic words and the second pool containing 15 three-syllable words. The short and long words were equated for frequency, concreteness, imageability, and familiarity (Bireta et al., 2010). On each trial, 7 words were randomly chosen from the pool of the condition for that trial.
Design and procedure The design and procedure were the same as those in Experiment 1A.

\section{Results}

As is illustrated in Fig. 4, there appears to be a word length effect in the forward recall condition, which was diminished in backward recall. The analysis indicated that backward recall $(M=.48, S D=.09)$ was superior to forward recall $(M=.41, S D=.10)$ and that short words $(M=.50$, $S D=.11)$ were better recalled than long words $(M=.40$, $S D=.08)$. The main effect of serial position was significant. Of particular importance, the interaction between recall direction and word length was found to be significant. The word length effect was weaker in backward recall for this experiment, but planned contrasts showed that the effect was still significantly present in both forward and backward recall (see Table 1). The interaction between serial position and recall direction was significant, due to the greater primacy effect in forward recall and recency effect in backward recall. The interaction between word length and serial position was also significant, but not the three-way interaction between recall direction, word length, and serial position.

\section{Discussion}

Experiment 5 replicated the classic word length effect, with a better recall for short words over long words (see, e.g., Baddeley et al., 1975). Of critical importance, Experiment 5 showed that when Bireta et al.'s (2010) stimuli were used, the effect of word length was almost abolished in backward recall. Indeed, as is shown in Table 1, the magnitude of the word length effect decreased from $29.5 \%$ in forward recall to $10.7 \%$ in backward recall. This reduction of $18.8 \%$ between the two recall conditions is even greater than that observed by Bireta et al. (2010), who observed a reduction of $15.2 \%$.

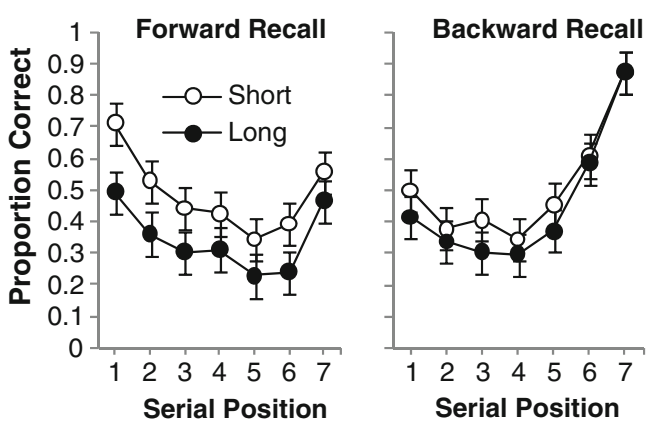

Fig. 4 Proportion of correct responses as a function of serial position and word length, in the forward and backward recall directions in Experiment 5. Errors bars represent 95\% confidence intervals 


\section{General discussion}

The objective of the present study was to revisit the effects of phonological similarity, irrelevant speech, articulatory suppression, and word length in forward and backward recall using open and closed pools of words. The results showed that all four phenomena were observed in both forward and backward recall, irrespective of set size.

\section{Explaining Bireta et al.'s (2010) results}

The results reported in the present study are in sharp contrast with those of Bireta et al. (2010; Surprenant et al., 2011: Bireta et al. showed that the four benchmark memory phenomena were abolished or greatly diminished in backward recall. The abolition of benchmark memory effects cannot be attributed to the use of a closed word pool. Indeed, we showed that the four benchmark memory effects were observed using both an open and a closed pool of words. The discrepancy between our results and those of Bireta and her colleagues, however, might be due to their stimulus set. For instance, because of the selection method used by Bireta et al., it is possible that the stimulus sets they used were much more impoverished in meaning, as compared with our own stimuli, and, as a consequence, participants relied more heavily on seriation in their study. The hypothesis that the discrepancy between our results and theirs is due to the stimulus set was confirmed by our last experiment: When we used the same set of words as that used by Bireta et al., the recall advantage for short words over long words was severely reduced, decreasing from $29.5 \%$ in forward recall to $10.7 \%$ in backward recall.

For the experiments on irrelevant speech and phonological similarity, Bireta et al. (2010) used closed sets of letters that were the same for all participants. It can be argued that their results with letters were due to the extreme familiarity of letters, as compared with words. However, as was shown in Experiment 1B, increasing familiarity with the stimulus set did not modulate the interaction between recall direction and phonological similarity. Although no definite explanation can be provided for the abolition of phonological similarity and irrelevant speech effects in backward recall using letters, lexical representations are a likely candidate. Indeed, words have a lexical representations in long-term memory, while, to all practical means, letters do not.

The present study is not the first one to suggest that the stimulus set selected is responsible for the effects that are observed. For instance, Bireta, Neath, and Surprenant (2006; see also Jalbert, Neath, Bireta, \& Surprenant, 2011) showed that the stimulus set used modulated the word length effect when short and long words were presented in alternation in a list. On the one hand, this assumption warrants great care when selecting stimuli in order to test memory processes. On the other hand, it does not explain why, when letters or these specific word sets were used, Bireta et al. (2010) abolished the four benchmark memory phenomena.

The presence of results diametrically opposed to those observed by Bireta et al. (2010; Surprenant et al., 2011) in the nine experiments of the present series and the attribution of this difference to the word sets naturally raise the issue of items' representativeness. In both of their articles, Bireta and her colleagues used a total of 54 different words and 15 different letters. In the present series of experiments, we used 980 different words (one set of 196 words in Experiment 1; one set of 392 words in Experiments 2 and 3; and one set of 392 words in Experiment 4). We think that our 980 words are potentially more representative than the 54 words of Bireta et al. and, therefore, that our results are more likely to be replicated in future studies. This idea is comforted by the fact that in addition to the present study, other studies have shown that backward recall had no effect on memory phenomena (see, e.g., Guérard \& Saint-Aubin, in press; Walker \& Hulme, 1999). Undoubtedly, uncovering the key characteristic shared by Bireta et al.'s (2010) stimuli will shed light on the processes underpinning backward recall.

\section{Implications for backward recall}

In order to account for the effect of backward recall on the four benchmark memory effects, Bireta et al. (2010) suggested that when participants are required to recall items in the reverse order, attention to the order dimension is increased. Backward recall would necessitate more resources for order processing at the expense of item processing (see also Delosh \& McDaniel, 1996). Therefore, the effects found in forward recall that are attributed to distinctiveness along the item dimension would be abolished in backward recall. This interpretation was challenged by Guérard and Saint-Aubin (in press), who showed that four phenomena that mainly affect the retention of item information - that is, the effects of semantic similarity, word frequency, lexicality, and imageability - were unaffected by backward recall (see also Walker \& Hulme, 1999). According to Bireta et al.'s view, the four benchmark memory effects - that is, the effects of word length, phonological similarity, articulatory suppression, and irrelevant speech - are attributed to the item dimension. The item and order trade-off hypothesis predicts that they should be modulated by recall direction. However, this was not the case in the present study. Therefore, the item and order tradeoff hypothesis cannot account for the present results.

In order to explain the discrepancy between Bireta et al.'s (2010; Surprenant et al., 2011) findings and those with 
lexical effects, Guérard and Saint-Aubin (in press) suggested that the processes underlying benchmark memory effects and lexical effects were modulated differently by recall direction. In agreement with the modal view in the field, lexical effects can be accounted for by calling upon redintegration processes (see, e.g., Hulme et al., 1991; Saint-Aubin, Ouellette, \& Poirier, 2005; Stuart \& Hulme, 2009). To put it in a nutshell, during recall, degraded phonological representations must undergo a deblurring or reconstruction process before being output as a response. Long-term lexical representations would be used to support this reconstruction process, which would be insensitive to recall direction. The memory processes underlying benchmark memory effects, on the other hand, would be affected by recall direction, since immediate serial recall performance would be based on item and order processes.

The present study does not allow questioning the idea that lexical effects and benchmark memory phenomena depend on distinct processes. It clearly shows, however, that none of these processes are affected by recall direction.

The present study is consistent with previous research showing that memory phenomena, such as the effects of semantic similarity, word frequency, lexicality, and imageability, were unaffected by backward recall (Guérard \&
Saint-Aubin, in press; Walker \& Hulme, 1999). Together, these studies suggest that the processes underlying lexical effects and benchmark memory phenomena are not affected differently by backward recall. One parsimonious explanation that can account for the effect of backward recall is the principle of output interference (see Li \& Lewandowsky, 1995): As items are output, the items not yet recalled are degraded and become more difficult to recall. In backward recall, the first items output are the last list's items. Therefore, these items suffer less from output interference, as compared with initial list's items, leading to a greater recency than primacy. In forward recall, recency is weaker than primacy because the last list's items are degraded during the recall of the first list's items.

In conclusion, the present study shows that benchmark memory effects well known to affect forward serial recall are all observed in backward serial recall. We are confident that these results will be easily replicable, since they were found with a large range of words. Overall, the present findings allowed understanding further the mechanisms underpinning backward recall. More precisely, they suggest that a parsimonious account based on the principle of output interference is sufficient to account for the effect of backward recall.

\section{Appendix 1}

Table 2 Analyses of variance for the proportion of correct recall in Experiments 1-5

\begin{tabular}{|c|c|c|c|c|c|c|c|c|c|c|c|c|c|c|c|c|}
\hline \multirow[b]{3}{*}{ Source } & \multirow[b]{3}{*}{$d f$} & \multicolumn{8}{|c|}{ Phonological Similarity } & \multicolumn{7}{|c|}{ Irrelevant Speech } \\
\hline & & \multicolumn{4}{|c|}{ Open Pool (Exp. 1A) } & \multicolumn{4}{|c|}{ Closed Pool (Exp. 1B) } & \multicolumn{3}{|c|}{ Open Pool (Exp. 2A) } & \multicolumn{4}{|c|}{ Closed Pool (Exp. 2B) } \\
\hline & & \multicolumn{2}{|l|}{$F$} & $M S E$ & $\eta_{p}^{2}$ & $F$ & MSE & \multicolumn{2}{|c|}{$\eta_{p}^{2}$} & $F$ & MSE & $\eta_{p}^{2}$ & \multicolumn{2}{|c|}{$F$} & $M S E$ & $\eta_{p}^{2}$ \\
\hline $\mathrm{RD}$ & 1,19 & 1.58 & & .07 & .08 & 1.54 & .05 & & & 0.65 & .04 & .03 & 0 . & & .05 & .05 \\
\hline Mem & 1,19 & 16.52 & & .12 & .47 & $22.33^{*}$ & .08 & & & $23.67^{*}$ & .04 & .56 & & & .03 & .75 \\
\hline SP & 6,114 & 36.58 & & .08 & .66 & $21.70^{*}$ & .05 & & & $38.72 *$ & .08 & .67 & & & .15 & .48 \\
\hline $\mathrm{RD} \times \mathrm{Mem}$ & 1,19 & 0.03 & & .03 & .00 & 0.82 & .02 & & & 0.17 & .04 & .01 & & & .03 & .12 \\
\hline $\mathrm{RD} \times \mathrm{SP}$ & 6,114 & 26.38 & & .03 & .58 & $38.11 *$ & .04 & & & $55.81^{*}$ & .01 & .75 & & & .02 & .60 \\
\hline $\mathrm{Mem} \times \mathrm{SP}$ & 6,114 & $2.40^{*}$ & & .01 & .11 & 2.16 & .01 & & & $2.26^{*}$ & .01 & .11 & & & .01 & .13 \\
\hline \multirow[t]{3}{*}{$\mathrm{RD} \times \mathrm{Mem} \times \mathrm{SP}$} & 6,114 & 0.63 & & .01 & .03 & 1.18 & .01 & & & 0.29 & .01 & .02 & & & .01 & .01 \\
\hline & & \multicolumn{6}{|c|}{ Articulatory Suppression } & \multicolumn{9}{|c|}{ Word Length } \\
\hline & & \multicolumn{3}{|c|}{ Open Pool (Exp. 3A) } & \multicolumn{3}{|c|}{ Closed Pool (Exp. 3B) } & \multicolumn{3}{|c|}{ Open Pool (Exp. 4A) } & \multicolumn{3}{|c|}{ Closed Pool (Exp. 4B) } & \multicolumn{3}{|c|}{ Semi-closed (Exp. 5) } \\
\hline Source & $d f$ & $F$ & $M S E$ & $\eta_{p}^{2}$ & $F$ & $M S E$ & $\eta_{p}^{2}$ & $F$ & $M S E$ & $\eta_{p}^{2}$ & $F$ & $M S E$ & $\eta_{p}^{2}$ & $F$ & $M S E$ & $\eta_{p}^{2}$ \\
\hline $\mathrm{RD}$ & 1,19 & 0.52 & .03 & .03 & 0.98 & .02 & .05 & $18.42 *$ & .03 & .49 & 1.70 & .05 & .08 & $11.04 *$ & .06 & .37 \\
\hline Mem & 1,19 & $104.86^{*}$ & .06 & .85 & $70.66^{*}$ & .06 & .79 & $27.70^{*}$ & .07 & .59 & $36.02 *$ & .04 & .66 & $28.10^{*}$ & .05 & .60 \\
\hline SP & 6,114 & $30.90^{*}$ & .10 & .62 & $44.97 *$ & .06 & .70 & $49.52 *$ & .07 & .72 & $47.97 *$ & .06 & .72 & $31.09 *$ & .10 & .62 \\
\hline $\mathrm{RD} \times \mathrm{Mem}$ & 1,19 & $6.02 *$ & .02 & .24 & 3.10 & .02 & .14 & 1.72 & .03 & .08 & 0.11 & .03 & .01 & $8.68^{*}$ & .03 & .31 \\
\hline $\mathrm{RD} \times \mathrm{SP}$ & 6,114 & $27.50^{*}$ & .01 & .59 & $28.70^{*}$ & .02 & .60 & $39.13^{*}$ & .01 & .67 & $30.93 *$ & .03 & .62 & $34.50^{*}$ & .02 & .65 \\
\hline $\mathrm{Mem} \times \mathrm{SP}$ & 6,114 & $3.61 *$ & .03 & .16 & 2.30 & .03 & .11 & $3.78 *$ & .01 & .17 & $2.53^{*}$ & .02 & .12 & $2.15^{*}$ & .01 & .10 \\
\hline $\mathrm{RD} \times \mathrm{Mem} \times \mathrm{SP}$ & 6,114 & 1.64 & .01 & .08 & $8.09^{*}$ & .01 & .30 & 0.61 & .01 & .03 & 0.39 & .01 & .02 & 0.98 & .01 & .05 \\
\hline
\end{tabular}

$\mathrm{Mem}=$ benchmark memory phenomenon, $\mathrm{RD}=$ recall direction, $\mathrm{SP}=$ serial position

$* p<.05$ 


\section{Appendix 2}

Table 3 Analyses of variance for the combined analyses in Experiments 1-4

\begin{tabular}{|c|c|c|c|c|c|c|c|}
\hline \multirow[b]{2}{*}{ Source } & \multirow[b]{2}{*}{$d f$} & \multicolumn{3}{|c|}{ Phonological Sim. (Exp. 1A \& 1B) } & \multicolumn{3}{|c|}{ Irrelevant Speech (Exp. 2A \& 2B) } \\
\hline & & $F$ & $M S E$ & $\eta_{p}^{2}$ & $F$ & $M S E$ & $\eta_{p}^{2}$ \\
\hline $\mathrm{RD}$ & 1,38 & $3.11 *$ & .01 & .08 & 0.03 & .01 & .00 \\
\hline Mem & 1,38 & $37.57 *$ & .01 & .50 & $75.95^{*}$ & .01 & .67 \\
\hline Pool & 1,38 & 4.66 & .08 & .11 & 0.15 & .05 & .00 \\
\hline $\mathrm{RD} \times$ Pool & 1,38 & 0.02 & .01 & .00 & 1.56 & .01 & .04 \\
\hline Mem $\times$ Pool & 1,38 & 0.04 & .01 & .00 & 2.72 & .01 & .07 \\
\hline $\mathrm{RD} \times \mathrm{Mem}$ & 1,38 & 0.50 & .00 & .01 & 1.80 & .01 & .05 \\
\hline \multirow[t]{2}{*}{$\mathrm{RD} \times$ Mem $\times$ Pool } & 1,38 & 0.19 & .00 & .01 & 0.50 & .01 & .01 \\
\hline & & \multicolumn{3}{|c|}{ Articulatory Supp. (Exp. 3A \& 3B) } & \multicolumn{3}{|c|}{ Word Length (Exp. 4A \& 4B) } \\
\hline Source & $d f$ & $F$ & $M S E$ & $\eta_{p}^{2}$ & $F$ & $M S E$ & $\eta_{p}^{2}$ \\
\hline $\mathrm{RD}$ & 1,38 & 0.00 & .00 & .00 & $52.78^{*}$ & .01 & .58 \\
\hline Mem & 1,38 & $174.72 *$ & .01 & .82 & $56.10^{*}$ & .01 & .60 \\
\hline Pool & 1,38 & 2.92 & .03 & .07 & 1.77 & .05 & .04 \\
\hline $\mathrm{RD} \times$ Pool & 1,38 & 1.40 & .00 & .04 & $29.15^{*}$ & .01 & .43 \\
\hline Mem $\times$ Pool & 1,38 & 2.88 & .01 & .07 & 0.00 & .01 & .00 \\
\hline $\mathrm{RD} \times \mathrm{Mem}$ & 1,38 & $8.82 *$ & .00 & .19 & 0.57 & .00 & .02 \\
\hline RD $\times$ Mem $\times$ Pool & 1,38 & 0.19 & .00 & .01 & 0.09 & .00 & .00 \\
\hline
\end{tabular}

Mem = benchmark memory phenomenon, $\mathrm{RD}=$ recall direction

$* p<.05$

\section{Lists used in Experiment 1}

nb. Lists in the similar conditions are presented horizontally (e.g., paix, craie, frais, mets, plaie, vraie, trait). Lists in the dissimilar conditions are presented vertically (e.g., paix, grue, joint, nuit, banc, veau, toux)

\begin{tabular}{|c|c|c|c|c|c|c|}
\hline \multicolumn{7}{|l|}{ Set 1} \\
\hline paix & craie & frais & mets & plaie & vraie & trait \\
\hline [peace] & [chalk] & [expenses] & [dish] & [wound] & [truth] & [feature] \\
\hline rue & lu & fût & vue & nue & bru & pus \\
\hline [street] & [read] & [barrel] & [sight] & [nude] & [daughter-in-law] & [pus] \\
\hline grain & loin & fin & train & frein & nain & lien \\
\hline [grain] & {$[$ far $]$} & [end] & [train] & [brake] & [dwarf] & [bond] \\
\hline banc & dent & gant & plan & rang & vent & sang \\
\hline [bench] & [tooth] & [glove] & [map] & [rank] & [wind] & [blood] \\
\hline $\operatorname{maux}$ & tôt & chiot & saut & lot & flot & chaud \\
\hline [pain] & [early] & [pup] & [jump] & [batch] & [flood] & [heat] \\
\hline froid & plat & drap & joie & poids & proie & moi \\
\hline [cold] & [dish] & [cloth] & [joy] & [weight] & [prey] & [ego] \\
\hline blé & clef & dé & gai & fée & nez & quai \\
\hline [wheat] & {$[\mathrm{key}]$} & [dice] & [gay] & [fairy] & [nose] & [wharf] \\
\hline \multicolumn{7}{|l|}{ Set 2} \\
\hline plein & mien & $\operatorname{lin}$ & thym & clin & saint & rien \\
\hline [load] & [mine] & [linen] & [thyme] & [fillet] & [saint] & [naught] \\
\hline prêt & fait & grès & jet & lait & guet & raie \\
\hline [loan] & [fact $]$ & [sandstone] & [fountain] & [milk] & [lookout] & [stripe] \\
\hline frit & gui & plie & fruit & bruit & mie & brie \\
\hline [fried] & [mistletoe] & [plaice] & [fruit] & [noise] & [crumb] & [brie] \\
\hline
\end{tabular}




\begin{tabular}{|c|c|c|c|c|c|c|}
\hline grand & plant & sans & gens & cran & temps & dans \\
\hline [senior] & [seedling] & [without] & [people] & [notch] & [time] & [in] \\
\hline trou & coup & flou & loup & moue & sous & cou \\
\hline [hole] & [knock] & [vagueness] & [wolf] & [pout] & [cash] & [neck] \\
\hline vœu & pieux & vieux & queue & jeu & mieux & deux \\
\hline [wish] & [pious] & [old] & [tail] & [game] & [best] & [two] \\
\hline blond & long & jonc & prompt & rond & thon & pont \\
\hline [blond] & [length] & [rush] & [swift] & [circle] & [tuna] & [bridge] \\
\hline \multicolumn{7}{|l|}{ Set 3} \\
\hline près & taie & quiet & muet & laid & niais & fouet \\
\hline [near] & [slip] & [calm] & [mute] & [ugly] & [simpleton] & [whip] \\
\hline joint & pin & vin & foin & sain & point & coin \\
\hline [joint] & [pine] & [wine] & [hay] & [lard] & [point] & [corner] \\
\hline nuit & riz & vie & ski & nid & prix & lit \\
\hline [night] & [rice] & [life] & [ski] & [nest] & [price] & [bed] \\
\hline franc & clan & quand & blanc & lent & gland & chant \\
\hline [franc] & [clan] & [when] & [white] & [slow] & [acorn] & [song] \\
\hline toux & roux & goût & clou & boue & doux & joue \\
\hline [cough] & [red] & [taste] & [nail] & [mud] & [goy] & [cheek] \\
\hline gras & bas & spa & tas & bras & gars & trois \\
\hline [fat] & [sock] & [spa] & [heap] & [arm] & [guy] & [three] \\
\hline fond & don & mont & bond & lion & nom & pion \\
\hline [bottom] & [gift] & [mount] & [jump] & [lion] & [name] & [pawn] \\
\hline \multicolumn{7}{|l|}{ Set 4} \\
\hline grue & cru & but & glu & flux & jus & dru \\
\hline [crane] & [vineyard] & [goal] & [glue] & [flow] & [juice] & [thick] \\
\hline veau & sceau & peau & mot & gros & haut & dos \\
\hline [calf] & [seal] & [skin] & [word] & [bulk] & [top] & [back] \\
\hline pneu & feu & yeux & dieu & bleu & creux & lieu \\
\hline [tire] & [fire] & [eyes] & [god] & [blue] & [hollow] & [place] \\
\hline puis & ouïe & truie & scie & gris & suie & cuit \\
\hline [then] & [hearing] & [sow] & [saw] & [gray] & [soot] & [cooked] \\
\hline ton & son & front & ion & plomb & scion & tronc \\
\hline [pitch] & [noise] & [forehead] & [ion] & [lead] & [scion] & [trunk] \\
\hline chat & noix & croix & doigt & foie & loi & soie \\
\hline [cat] & [nut] & [cross] & [finger] & [liver] & [law] & [silk] \\
\hline bain & chien & pain & main & vingt & gain & rein \\
\hline [bath] & [dog] & [bread] & [hand] & [twenty] & [profit] & [kidney] \\
\hline
\end{tabular}

Lists used in Experiments 2 and 3

\begin{tabular}{|c|c|c|c|c|c|c|}
\hline \\
\hline \multicolumn{7}{|l|}{$\begin{array}{l}\text { Set } 1 \\
\text { bond }\end{array}$} \\
\hline [jump] & [cape] & [lord] & [player] & [iron] & [batch] & [rat] \\
\hline ciel & os & gag & short & muet & prix & coup \\
\hline [sky] & [bone] & [gag] & [knickers] & [mute] & [price] & [knock] \\
\hline veuf & clic & noix & sketch & vis & duo & coin \\
\hline [widower] & [click] & [nut] & [sketch] & [screw] & [duet] & [corner] \\
\hline punch & nerf & fleur & plein & gras & rond & dieu \\
\hline [punch] & [nerve] & [flower] & [load] & [fat] & [circle] & [god] \\
\hline jazz & oie & lard & bail & loup & tri & blond \\
\hline
\end{tabular}




\begin{tabular}{|c|c|c|c|c|c|c|}
\hline [jazz] & [goose] & [bacon] & [lease] & [wolf] & [sorting] & [blond] \\
\hline ion & gel & quai & $\mathrm{sac}$ & foi & biais & tour \\
\hline [ion] & [frost] & [wharf] & [bag] & [faith] & [slant] & [turn] \\
\hline chips & tronc & golf & trait & chant & mat & bout \\
\hline [chips] & [trunk] & [golf] & [feature] & [song] & [checkmate] & [tip] \\
\hline air & foie & but & raie & chic & vers & sueur \\
\hline [air] & [liver] & [goal] & [stripe] & [knack] & [rhyme] & [sweat] \\
\hline pro & gaz & sou & frais & flirt & watt & pois \\
\hline [pro] & [gas] & [penny] & [expenses] & [flirting] & [watt] & [pea] \\
\hline bloc & clair & pieu & sang & stress & son & prêt \\
\hline [block] & [light] & [stake] & [blood] & [stress] & [noise] & [loan] \\
\hline steak & lieue & fée & loft & soir & pin & bal \\
\hline [steak] & [league] & [fairy] & [loft] & [evening] & [pine] & [ball] \\
\hline troll & nu & soif & pif & fait & voix & haut \\
\hline [troll] & [nude] & [thirst] & [nose] & [fact] & [voice] & [top] \\
\hline mer & moi & baie & dent & toast & star & coach \\
\hline [sea] & [ego] & [bay] & [tooth] & [toast] & [star] & [coach] \\
\hline grue & sir & chat & soin & cour & fil & char \\
\hline [crane] & [sir] & [cat] & [care] & [yard] & [wire] & [tank] \\
\hline banc & vif & bas & tout & zoom & pneu & sens \\
\hline [bench] & [raw] & [sock] & [whole] & [zoom] & [tire] & [way] \\
\hline snob & grain & pic & bac & vol & gris & toux \\
\hline [snob] & [grain] & [peak] & [tub] & [flight] & [gray] & [cough] \\
\hline pont & gong & mur & yeux & toit & grill & $\operatorname{arc}$ \\
\hline [bridge] & [bell] & [wall] & [eyes] & [roof] & [steakhouse] & [bow] \\
\hline court & rhum & cent & rue & ail & drap & corps \\
\hline [course] & [rum] & [hundred] & [street] & [garlic] & [cloth] & [body] \\
\hline train & dos & roue & art & gens & duc & long \\
\hline [train] & [back] & [wheel] & [art] & [people] & [duke] & [length] \\
\hline ouest & tas & pot & fruit & roux & pour & paie \\
\hline [west] & [heap] & [pot] & [fruit] & [red] & [pro] & [pay] \\
\hline grand & vœu & nord & jus & vie & greffe & cil \\
\hline [senior] & [wish] & [north] & [juice] & [life] & [transplant] & [lash] \\
\hline dard & $\operatorname{coq}$ & mort & droit & tic & roc & lien \\
\hline [dart] & [rooster] & [death] & [right] & [tic] & [rock] & [bond] \\
\hline $\max$ & veau & tank & lait & non & match & test \\
\hline$[\max ]$ & [calf] & [tank] & [milk] & [no] & [match] & [test] \\
\hline franc & sourd & gain & saut & suie & hall & plus \\
\hline [franc] & [deaf person] & [profit] & [jump] & [soot] & [hall] & [plus] \\
\hline bien & scout & yacht & clan & poids & surf & vert \\
\hline [good] & [boy scout] & [yacht] & [clan] & [weight] & [surfing] & [green] \\
\hline cieux & rein & mai & ours & rap & joie & truie \\
\hline [heaven] & [kidney] & [May] & [bear] & [rap] & [joy] & [sow] \\
\hline tir & pain & flanc & est & rock & coût & sot \\
\hline [shooting] & [bread] & [side] & [east] & [rock] & [cost] & [zany] \\
\hline stop & cuir & job & moeurs & cou & bar & sol \\
\hline [stop] & [leather] & [job] & [customs] & [neck] & [bar] & [ground] \\
\hline \multicolumn{7}{|l|}{ Set 2} \\
\hline sort & noir & chair & nul & soie & taux & bras \\
\hline [fate] & [black] & [flesh] & [idiot] & [silk] & [rate] & [arm] \\
\hline peur & fort & stock & plant & voie & pré & lion \\
\hline [fear] & [fort] & [stock] & [seedling] & [way] & [meadow] & [lion] \\
\hline
\end{tabular}




\begin{tabular}{|c|c|c|c|c|c|c|}
\hline trip & coeur & mal & front & nain & script & pie \\
\hline [trip] & [heart] & [pain] & [forehead] & [dwarf] & [script] & [magpie] \\
\hline col & tien & chou & deuil & bouc & vue & fils \\
\hline [collar] & [yours] & [cabbage] & [mourning] & [goat] & [sight] & [son] \\
\hline goût & flux & club & set & mois & tag & fouet \\
\hline [taste] & [flow] & [club] & [set] & [month] & [graffiti] & [whip] \\
\hline sport & parc & patch & plat & scotch & tract & craie \\
\hline [sport] & [park] & [patch] & [dish] & [scotch] & [pamphlet] & [chalk] \\
\hline souhait & don & haie & joue & or & chaud & rail \\
\hline [wish] & [gift] & [hedge] & [cheek] & [gold] & [heat] & [rail] \\
\hline vent & joug & plaie & joint & blé & flair & lieu \\
\hline [wind] & [yoke] & [wound] & [joint] & [wheat] & [intuition] & [place] \\
\hline gros & mets & bain & feu & cri & boeuf & froid \\
\hline [bulk] & [dish] & [bath] & [fire] & [shout] & [beef] & [cold] \\
\hline pli & gang & pet & mot & pub & fin & scalp \\
\hline [fold] & [gang] & [fart] & [word] & [saloon] & [end] & [scalp] \\
\hline lac & moins & rot & brun & choc & ouie & pouls \\
\hline [lake] & [minus] & [burp] & [brown] & [shock] & [hearing] & [pulse] \\
\hline brin & paix & duel & seau & jet & bord & thé \\
\hline [strand] & [peace] & [duel] & [bucket] & [fountain] & [edge] & [tea] \\
\hline volt & daim & gym & doigt & pion & lit & blanc \\
\hline [volt] & [deer] & [gym] & [finger] & [pawn] & [bed] & [white] \\
\hline boue & tin & cran & zinc & poil & nuit & pleur \\
\hline [mud] & [keelblock] & [notch] & [zinc] & [hair] & [night] & [tear] \\
\hline pou & chiot & bruit & fax & bec & foin & ton \\
\hline [lice] & [pup] & [noise] & {$[\mathrm{fax}]$} & [beak] & [hay] & [pitch] \\
\hline mars & rien & champ & doux & pied & thon & poing \\
\hline [March] & [naught] & [field] & [goy] & [foot $]$ & [tuna] & [fist $]$ \\
\hline proie & vin & gant & plouc & creux & pair & talc \\
\hline [prey] & [wine] & [glove] & [idiot] & [hollow] & [peer] & [talc] \\
\hline chef & frein & scie & jeep & gré & punk & trou \\
\hline [chief] & [brake] & [saw] & [jeep] & [liking] & [punk] & [hole] \\
\hline quart & chien & grec & fou & choeur & clef & jouet \\
\hline [quarter] & {$[\mathrm{dog}]$} & [greek] & [bishop] & [choir] & [key] & [toy $]$ \\
\hline guet & bol & spot & teint & queue & riz & cas \\
\hline [lookout] & [bowl] & [spot] & [complexion] & [tail] & [rice] & [case] \\
\hline ski & point & tact & part & peau & tort & sud \\
\hline [ski] & [point] & {$[\mathrm{tact}]$} & [portion] & [skin] & [wrong] & [south] \\
\hline four & plomb & puits & cerf & juin & mont & round \\
\hline [oven] & [lead] & [well] & [stag] & [June] & [mount] & [round] \\
\hline clin & froc & tard & proue & dur & ranch & juif \\
\hline [fillet] & [trousers] & [evening] & [prow] & [tough nut] & [ranch] & [jew] \\
\hline flash & $\operatorname{lin}$ & gourd & oeuf & ruée & clip & sel \\
\hline [flash] & [linen] & [heavy hand] & [egg] & [rush] & [clip] & [salt] \\
\hline sceau & fonds & rush & rang & seuil & porc & clou \\
\hline [seal] & [fund] & [dash] & [rank] & [threshold] & [pig] & [nail] \\
\hline soeur & août & as & trac & jeu & beau & dé \\
\hline [sister] & [August] & [ace] & [jitters] & [game] & [beauty] & [dice] \\
\hline nez & pas & kit & bois & saint & port & nid \\
\hline [nose] & [step] & [kit] & [wood] & [saint] & [port] & [nest] \\
\hline sein & croix & tiers & mou & flot & lueur & nom \\
\hline [breast] & [cross] & [third] & [wimp] & [flood] & [gleam] & [name] \\
\hline
\end{tabular}


Lists used in Experiment 4

\begin{tabular}{|c|c|c|c|c|c|c|}
\hline \multicolumn{7}{|l|}{ Short words } \\
\hline saint & bond & fruit & coq & bouc & flot & four \\
\hline [saint] & [jump] & [fruit] & [rooster] & [goat] & [flood] & [oven] \\
\hline mets & suie & sou & fonds & gain & creux & chaux \\
\hline [dish] & [soot $]$ & [penny] & [fund] & [profit] & [hollow] & [lime] \\
\hline soie & parc & tiers & frais & bol & char & ouest \\
\hline [silk] & [park] & [third] & [expenses] & [bowl] & [tank] & [west] \\
\hline roux & star & pair & lion & zinc & bœuf & jet \\
\hline [red] & [star $]$ & [peer] & [lion $]$ & [zinc] & [beef] & [fountain] \\
\hline tic & plein & club & tronc & lait & chaud & fût \\
\hline [tic] & [load $]$ & [club] & [trunk] & [milk] & [heat] & [barrel] \\
\hline rail & loi & moue & clou & craie & poil & ver \\
\hline [rail] & [law $]$ & [pout] & [nail] & [chalk] & [hair] & [worm] \\
\hline clown & foie & grain & proue & but & rang & puits \\
\hline [clown] & [liver] & [grain] & [prow] & [goal] & [rank] & [well] \\
\hline haie & juin & bac & jazz & gris & pif & clerc \\
\hline [hedge] & [June] & [tub] & [jazz] & [gray] & [nose] & [clerk] \\
\hline oie & fée & cran & rat & rein & chou & chœur \\
\hline [goose] & [fairy] & [notch] & [rat] & [kidney] & [cabbage] & [choir] \\
\hline cap & $\operatorname{arc}$ & jus & frein & saut & lourd & cent \\
\hline [cape] & [bow] & [juice] & [brake] & [jump] & [heavy] & [hundred] \\
\hline noix & rien & œuf & plomb & bar & cil & clair \\
\hline [nut] & [naught] & [egg] & [lead] & [bar] & [lash] & [light] \\
\hline nerf & sport & jouet & blé & gant & duc & scie \\
\hline [nerve] & [sport] & [toy] & [wheat] & [glove] & [duke] & [saw] \\
\hline doux & fric & golf & lard & froc & bloc & proie \\
\hline [goy] & [money] & [golf] & [bacon] & [trousers] & [block] & [prey] \\
\hline joint & tsar & vis & clef & fou & lieue & plaie \\
\hline [joint] & [tsar] & [screw] & {$[\mathrm{key}]$} & [bishop] & [league] & [wound] \\
\hline rond & veau & sud & fouet & pli & août & pieu \\
\hline [circle] & [calf] & [south] & [whip] & [fold] & [August] & [stake] \\
\hline guet & jonc & trot & soif & pic & flux & moeurs \\
\hline [lookout] & [rush] & [trot] & [thirst] & [peak] & [flow] & [customs] \\
\hline gré & prêt & vol & croc & riz & nain & plus \\
\hline [liking] & [loan] & [flight] & [fang] & [rice] & [dwarf] & [plus] \\
\hline pois & mai & teint & match & cerf & clé & gaz \\
\hline [pea] & [May] & [complexion] & [match] & [deer] & {$[\mathrm{key}]$} & [gas] \\
\hline lot & tir & boue & clan & mie & choix & seuil \\
\hline [batch] & [shooting] & [mud] & [clan] & [crumb] & [choice] & [threshold] \\
\hline grec & lien & seau & bus & queue & mars & roc \\
\hline [greek] & [bond] & [bucket] & [bus] & [tail] & [March] & [rock] \\
\hline croix & pin & veuf & raie & pneu & pleur & bourg \\
\hline [cross] & [pine] & [widower] & [stripe] & [tire] & [tear] & [town] \\
\hline pré & trac & baie & mât & sel & $\operatorname{lin}$ & cru \\
\hline [meadow] & [jitters] & [bay] & [mast] & [salt] & [linen] & [vineyard] \\
\hline lac & nid & brin & vif & roue & porc & dé \\
\hline [lake] & [nest] & [strand] & [bait] & [wheel] & [pork] & [dice] \\
\hline bec & ours & mont & bal & moins & faux & gel \\
\hline
\end{tabular}




\begin{tabular}{|c|c|c|c|c|c|c|}
\hline [beak] & [bear] & [mount] & [ball] & [minus] & [false] & [frost] \\
\hline chant & joueur & choc & daim & toux & gras & pot \\
\hline [song] & [player] & [shock] & [deer] & [cough] & [fat $]$ & [pot] \\
\hline loup & ail & ski & as & foin & flanc & vœu \\
\hline [wolf] & [garlic] & [ski] & [ace] & [hay] & [side] & [wish] \\
\hline don & test & thé & souhait & os & tort & pou \\
\hline [gift] & [test] & [tea] & [wish] & [bone] & [wrong] & [lice] \\
\hline crin & pion & sort & tract & gars & vrai & deuil \\
\hline [horsehair] & [pawn] & [fate] & [pamphlet] & [guy] & [truth] & [mourning] \\
\hline \multicolumn{7}{|l|}{ Long words } \\
\hline pharmacie & peuplier & chirurgien & chevalet & paysan & punition & arsenal \\
\hline [pharmacy] & [poplar] & [surgeon] & [easel] & [peasant] & [punishment] & [arsenal] \\
\hline olivier & ornement & poésie & éventail & ensemble & pantalon & procureur \\
\hline [olive tree] & [ornament] & [poetry] & [range] & [set] & [pants] & [prosecutor] \\
\hline ingénieur & incendie & document & garage & division & écureuil & déjeuner \\
\hline [engineer] & [fire $]$ & [document] & [garage] & [division] & [squirrel] & [breakfast] \\
\hline caméra & aliment & barrage & agonie & escabeau & bataillon & entrevue \\
\hline [camera] & [food] & {$[\mathrm{dam}]$} & [agony] & [stepladder] & [battalion] & [interview] \\
\hline écrivain & assistant & cardinal & réception & inspecteur & cheminée & harmonie \\
\hline [writer] & [assistant] & [cardinal] & [reception] & [inspector] & [chimney] & [harmony] \\
\hline industrie & professeur & commerçant & élection & musicien & araignée & lavabo \\
\hline [industry] & [professor] & [trader] & [election] & [musician] & [spider] & {$[\operatorname{sink}]$} \\
\hline ascenseur & accident & capuchon & estomac & barbelé & détenu & biographie \\
\hline [elevator] & [accident] & [hood] & [stomach] & [barbwire] & [inmate] & [biography] \\
\hline atelier & argument & carillon & amateur & gouverneur & citoyen & capital \\
\hline [workshop] & [argument] & [bells] & [amateur] & [governor] & [citizen] & [capital] \\
\hline alibi & carnaval & irruption & robinet & syndicat & bouclier & océan \\
\hline [alibi] & [carnival] & [irruption] & [faucet] & [union] & [shield] & [ocean] \\
\hline producteur & policier & éléphant & énergie & pyjama & construction & inconnu \\
\hline [producer] & [policeman] & [elephant] & [energy] & [pyjama] & [construction] & [stranger] \\
\hline instrument & rédaction & embarras & entretien & ouvrier & cabaret & travailleur \\
\hline [instrument] & [essay] & [embarrassment] & [maintenance] & [workman] & [cabaret] & [worker] \\
\hline cinéma & radiateur & compliment & hôpital & horizon & cavalier & colonie \\
\hline [cinema] & [radiator] & [compliment] & [hospital] & [horizon] & [horseman] & [colony] \\
\hline cylindre & chemisier & champignon & oasis & tragédie & tremblement & parasol \\
\hline [cylinder] & [blouse] & [mushroom] & [oasis] & [tragedy] & [tremor] & [parasol] \\
\hline projecteur & parapluie & jardinière & réservoir & colonel & collection & restaurant \\
\hline [projector] & [umbrella] & [gardener] & [reservoir] & [colonel] & [collection] & [restaurant] \\
\hline moniteur & bâtiment & hiérarchie & haricot & examen & chevalier & destruction \\
\hline [monitor] & [building] & [hierarchy] & [bean] & [exam] & [knight] & [destruction] \\
\hline officier & appareil & étalon & étudiant & aquarium & vendredi & voyageur \\
\hline [officer] & [apparatus] & [stallion] & [student] & [aquarium] & [friday] & [traveller] \\
\hline illusion & paradis & canapé & visiteur & oreiller & hurlement & tabouret \\
\hline [illusion] & [paradise] & [sofa] & [visitor] & [pillow] & [scream] & [stool] \\
\hline agenda & explosion & festival & combattant & comédie & couturier & directeur \\
\hline [agenda] & [explosion] & [festival] & [fighter] & [comedy] & [designer] & [director] \\
\hline habitant & compagnon & univers & maladie & cabinet & serviteur & prisonnier \\
\hline [resident] & [companion] & [universe] & [disease] & [office] & [servant] & [prisoner] \\
\hline casino & mercredi & majesté & spectateur & monument & saucisson & corridor \\
\hline [casino] & [Wednesday] & [majesty] & [spectator] & [monument] & [sausage] & [corridor] \\
\hline pistolet & passager & historien & parlement & étendue & fondation & fantaisie \\
\hline [pistol] & [passenger] & [historian] & [parliament] & [area] & [foundation] & [fantasy] \\
\hline
\end{tabular}




\begin{tabular}{|c|c|c|c|c|c|c|}
\hline chocolat & animal & retenue & papillon & cuisinier & épaisseur & artisan \\
\hline [chocolate] & [animal] & [restraint] & [butterfly] & [cook] & [thickness] & [artisan] \\
\hline citation & conducteur & aboiement & amoureux & bourgeoisie & écolier & candidat \\
\hline [quote] & [driver] & [barking] & [lover] & [gentry] & [schoolboy] & [candidate] \\
\hline testament & autobus & mélodie & avenue & tablier & magasin & réunion \\
\hline [testament] & [bus] & [melody] & [avenue] & [apron] & [store] & [meeting] \\
\hline infirmier & profondeur & librairie & émission & souterrain & scénario & continent \\
\hline [nurse] & [depth] & [library] & [broadcasting] & [tunnel] & [scenario] & [continent] \\
\hline appétit & terminus & tourbillon & commandant & banane & escargot & cendrier \\
\hline [appetite] & [terminus] & [vortex] & [commander] & [banana] & [snail] & [ashtray] \\
\hline mobilier & invention & numéro & tribunal & président & opéra & perroquet \\
\hline [furniture] & [invention] & [number] & [court] & [president] & [opera] & [parrot] \\
\hline pharmacien & sifflement & pavillon & écurie & entonnoir & pâtissier & avocat \\
\hline [pharmacist] & [whistle] & [pavilion] & [stable] & [funnel] & [baker] & [lawyer] \\
\hline
\end{tabular}

\section{References}

Baddeley, A. D., Lewis, V. J., \& Vallar, G. (1984). Exploring the articulatory loop. Quarterly Journal of Experimental Psychology, $36 A, 233-252$.

Baddeley, A. D., Thomson, N., \& Buchanan, M. (1975). Word length and the structure of short-term memory. Journal of Verbal Learning and Verbal Behavior, 14, 575-589. doi:10.1016/ S0022-5371(75)80045-4

Banken, J. A. (1985). Clinical utility of considering Digits Forward and Digits Backward as separate components of the Wechsler Adult Intelligence Scale-Revised. Journal of Clinical Psychology, 41, 686-691. doi:10.1002/1097-4679(198509)41:5<686::AIDJCLP2270410517>3.0.CO;2-D.

Bireta, T. J., Fry, S. E., Jalbert, A., Neath, I., Surprenant, A. M., Tehan, G., et al. (2010). Backward recall and benchmark effects of working memory. Memory \& Cognition, 38, 279-291. doi:10.3758/MC.38.3.279

Bireta, T. J., Neath, I., \& Surprenant, A. M. (2006). The syllable-based word length effect and stimulus set specificity. Psychonomic Bulletin \& Review, 13, 434-438. doi:10.3758/BF03193866

Brown, G. D. A., Neath, I., \& Chater, N. (2007). A temporal ratio model of memory. Psychological Review, 114, 539-576. doi:10.1037/0033-295X.114.3.539

Colle, H. A., \& Welsh, A. (1976). Acoustic masking in primary memory. Journal of Verbal Learning and Verbal Behavior, 15, 17-31. doi:10.1016/S0022-5371(76)90003-7

Conrad, R. (1964). Acoustic confusions in immediate memory. British Journal of Psychology, 55, 75-84. doi:10.1111/j.20448295.1964.tb00899.x

Cowan, N., Lichty, W., \& Grove, T. R. (1990). Properties of memory for unattended spoken syllables. Journal of Experimental Psychology. Learning, Memory, and Cognition, 16, 258-269. doi: $10.1037 / 0278-7393.16 .2 .258$

DeLosh, E. L., \& McDaniel, M. A. (1996). The role of order information in free recall: Application to the word-frequency effect. Journal of Experimental Psychology: Learning, Memory, and Cognition, 22, 1136-1146. doi:10.1037//0278-7393.22.5.1136

Guérard, K., \& Saint-Aubin, J. (in press). Assessing the effect of lexical variables in backward recall. Journal of Experimental Psychology: Learning, Memory, and Cognition. doi:10.1037/a0025481

Gupta, P., Lipinski, J., \& Aktunc, E. (2005). Re-examining the phonological similarity effect in immediate serial recall: The roles of type of similarity, category cueing, and item recall. Memory \& Cognition, 33, 1001-1016. doi:10.3758/BF03193208
Hulme, C., Maughan, S., \& Brown, G. D. A. (1991). Memory for familiar and unfamiliar words: Evidence for a long-term memory contribution to short-term memory span. Journal of Memory and Language, 30, 685-701. doi:10.1016/0749-596X (91) $90032-\mathrm{F}$

Hulme, C., Roodenrys, S., Brown, G. D. A., Schweickert, R., Martin, S., \& Stuart, G. (1997). Word-frequency effects on short-term memory tasks: Evidence for a redintegration process in immediate serial recall. Journal of Experimental Psychology: Learning, Memory, and Cognition, 23, 1217-1232. doi:10.1037//02787393.23.5.1217

Hulme, C., Stuart, G., Brown, G. D. A., \& Morin, C. (2003). High- and low-frequency words are recalled equally well in alternating lists: Evidence for associative effects in serial recall. Journal of Memory and Language, 49, 500-518. doi:10.1016/S0749-596X(03)00096-2

Jalbert, A., Neath, I., Bireta, T. J., \& Surprenant, A. M. (2011). When does length cause the word length effect? Journal of Experimental Psychology: Learning, Memory, and Cognition, 37, 338-353. doi: $10.1037 / \mathrm{a} 0021804$

Jones, D., \& Morris, N. (1992). Irrelevant speech and serial recall: Implications for theories of attention and working memory. Scandinavian Journal of Psychology, 33, 212-229. doi:10.1111/ j.1467-9450.1992.tb00911.x

LeCompte, D. C. (1996). Irrelevant speech, serial rehearsal, and temporal distinctiveness: A new approach to the irrelevant speech effect. Journal of Experimental Psychology. Learning, Memory, and Cognition, 22, 1154-1165. doi:10.1037//02787393.22.5.1154

Lewandowsky, S., \& Farrell, S. (2008). Short-term memory: New data and a model. In B. H. Ross (Ed.), The psychology of learning and motivation (Vol. 49, pp. 1-48). London: Elsevier. doi:10.1016/ S0079-7421(08)00001-7

Li, S.-C., \& Lewandowsky, S. (1995). Forward and backward recall: Different retrieval processes. Journal of Experimental Psychology: Learning, Memory, and Cognition, 21, 837-847. doi:10.1037// 0278-7393.21.4.837

Miller, L. M., \& Roodenrys, S. (2009). The interaction of word frequency and concreteness in immediate serial recall. Memory \& Cognition, 37, 850-865. doi:10.3758/MC.37.6.850

Multhaup, K. S., Balota, D. A., \& Cowan, N. (1996). Implications of aging, lexicality, and item length for the mechanisms underlying memory span. Psychonomic Bulletin \& Review, 3, 112-120. doi:10.3758/BF03210750

Murray, D. J. (1968). Articulation and acoustic confusability in shortterm memory. Journal of Experimental Psychology, 78, 679-684. doi:10.1037/h0026641 
Poirier, M., \& Saint-Aubin, J. (1995). Memory for related and unrelated words: Further evidence on the influence of semantic factors in immediate serial recall. Quarterly Journal of Experimental Psychology, 48A, 384-404.

Reynolds, C. R. (1997). Forward and backward memory span should not be combined for clinical analysis. Archives of Clinical Neuropsychology, 12, 29-40. doi:10.1016/S0887-6177(96) 00015-7

Roodenrys, S., \& Quinlan, P. T. (2000). The effects of stimulus set size and word frequency on verbal serial recall. Memory, 8, 7178. doi:10.1080/096582100387623

Saint-Aubin, J., Ouellette, D., \& Poirier, M. (2005). Semantic similarity and immediate serial recall: Is there an effect on all trials? Psychonomic Bulletin \& Review, 12, 171-177. doi:10.3758/ BF03196364

Saint-Aubin, J., \& Poirier, M. (1999). The influence of long-term memory factors on immediate serial recall: An item and order analysis. International Journal of Psychology, 34, 347-352. doi:10.1080/002075999399675
Stuart, G., \& Hulme, C. (2009). Lexical and semantic influences on immediate serial recall: A role for redintegration. In A. Thorn \& $\mathrm{M}$. Page (Eds.), Interactions between short-termand long-term memory in the verbal domain (pp. 157-176). New York: Psychology Press.

Surprenant, A. M., Bireta, T. J., Brown, M. A., Jalbert, A., Tehan, G., \& Neath, I. (2011). Backward recall and the word length effect. The American Journal of Psychology, 124, 75-86.

Surprenant, A. M., Neath, I., Bireta, T. J., \& Allbritton, D. (2008). Directly assessing the relationship between irrelevant speech and irrelevant tapping. Canadian Journal of Experimental Psychology, 62, 141-149.

Tse, C.-S. (2009). The role of associative strength in the semantic relatedness effect on immediate serial recall. Memory, 17, 874891. doi:10.1080/09658210903376250

Walker, I., \& Hulme, C. (1999). Concrete words are easier to recall than abstract words: Evidence for a semantic contribution to short-term serial recall. Journal of Experimental Psychology: Learning, Memory, and Cognition, 25, 1256-1271. doi:10.1037// 0278-7393.25.5.1256 